\title{
Improvement of the Properties of Gray Cast Iron by Silicon Dioxide and Carbon Nanostructures
}

\author{
Victor V. Kondratyev*, \\ Nikolay A. Ivanov, Andrey E. Balanovskiy, \\ Nikolay N. Ivanchik and Antonina I. Karlina \\ Irkutsk National Research Technical University \\ 83 Lermontova, Irkutsk, 664074, Russia
}

Received 09.04.2016, received in revised form 28.05.2016, accepted 20.06.2016

\begin{abstract}
Increasing requirements in terms of performance in modern industry forced to use materials that can operate at higher loads. For metallurgical industry production increasingly require the casting of gray cast iron (GI) high marks. Improving the properties of cast iron and steel is achieved only through the effective doping and modification, allowing to eliminate defects, to grind grain. Currently, the industry uses over 500 existing types of modifiers, most of them are multicomponent. Amount of various additives vary from 2 to 15 components. Very often the main component of additives is silicon-effective graphitizer and deoxidizer. Additives remaining components serve to enhance the effect of modification, increase "survivability" of modifiers, and to change the shape of inclusions of graphite in the iron. Frequently alloying additives are rare earth metals, and other components, considerably raising the price of the final product.

At present, the highly competitive component requires an efficiency modifiers, considering the economic component. For this purpose, this paper investigated the effect of nano-additives with high chemical reactivity of carbon and silicon. The theoretical aspects of the modification and the main difficulties that do not fit into the framework of the theory of nucleation are explored. Cast iron modification process made by three different formulations of modifiers, including:

- Composition 1 -Replaced $50 \%$ of standard metallurgical graphite particulate graphitic carbon with a content of $0.20 \%$ by weight. carbon multiwalled nanotubes.

- Composition 2 - nanograins silica (89-90\%) + amorphous carbon in different concentrations.

- Composition 3 - blend compositions 1 and 2 in the proportion of 30 to $70 \%$.

Smelting of gray iron took place in standard mode according to the current smelting technology instruction. Casting the melt in two ways:

1) Fill the melt on top of the modifier

2) "sandwich" process.

Evaluation of modifier performed using test strength at break the modified samples. Modifiers all formulations showed a temporary increase in resistance (HB). The tested samples were subjected to the study by scanning electron microscopy (SEM). The theoretical justification of efficiency of dispersed mixed modifiers
\end{abstract}

Keywords: modifiers, nanosilica, silicone dioxide, gray iron, multicomponent modifiers.

Citation: Kondratyev V.V., Ivanov N.A., Balanovskiy A.E., Ivanchik N.N., Karlina A.I. Improvement of the properties of gray cast iron by silicon dioxide and carbon nanostructures, J. Sib. Fed. Univ. Eng. technol., 2016, 9(5), 671-685. DOI: 10.17516/1999494X-2016-9-5-671-685.

(c) Siberian Federal University. All rights reserved

* Corresponding author E-mail address:kvv@istu.edu 


\title{
Улучшение свойств серого чугуна кремнийдиоксид \\ и углеродными наноструктурами
}

\author{
В.В. Кондратьев, Н.А. Иванов, \\ А.Е. Балановский, Н.Н. Иванчик, А.И. Карлина \\ Иркутский национальный \\ исследовательский технический университет \\ Россия, 664074, Иркутск, Лермонтова, 83
}

Повымение требований $к$ эксплуатационным характеристикам в современной промышленности вынуждает использовать материалы, способные работать при повышенных нагрузках. Не стала исключением металлургическая отрасль, где производству все чаще требуются отливки из серого чугуна (СЧ) высоких марок. Улучшение свойств серого чугуна и сталей достигается только за счет эффективного легирования $u$ модифицирования, позволяющего устранить дефекты, измельчить зерно. В настоящее время в промышленности используется свыше 500 действующих типов модификаторов, большинство из них многокомпонентные, количество различных добавок меняется от 2 до 15 компонентов. Очень часто основным компонентом является кремний - эффективный графитизатор и раскислитель. Добавки остальных компонентов служат для усиления эффекта модифицирования, повышения «живучести» модификаторов, а также для изменения формы включений графита в чугуне. Часто добавки для легирования представляют собой редкоземельные металлы и другие компоненты, значительно удорожающие конечный продукт.

В настоящее время при высокой конкурентной составляющей требуется повышение эффективности модификаторов с учетом экономической составляющей. Для этого в данной работе проведено исследование влияния нанодобавок с повышенной химической активностью углерода и кремния. Рассмотрены теоретические аспекты модифицирования, основные сложности, не вписывающиеся в рамки теории зарождения иентров кристаллизаиии. Произведено модифицирование чугуна тремя различными составами модификаторов, включающих в себя:

- состав 1 - заменено 50 \% стандартного металлургического графита на дисперсный графитизированный углерод с содержанием 0,20\% масс. углеродных многослойных нанотрубок;

- состав 2 - наногранулы диоксида кремния (89-90\%) + аморфный углерод в разных концентрациях;

- состав 3 - смесь составов 1 и 2 в пропориии $30 \%$ на $70 \%$.

Выплавка серого чугуна происходила в стандартном режиме плавки согласно действующей технологической инструкиии. Разливка расплава производилась двумя способами:

1) заливка расплава на модификатор сверху;

2) «сандвич»-прочесс.

Действие модификатора оченивали с помощью испытаний прочности модифицированных образиов наразрыв. Модификаторы всех составов показали прирост временного сопротивления (HB). Испытанные образиы подверглись исследованию методами сканирующей электронной микроскопии (СЭМ). Приведено теоретическое обоснование эффективности использования дисперсных смесевых модификаторов.

Ключевые слова: многокомпонентные модификаторы, наносилика, углеродные нанотрубки, диоксид кремния, серый чугун. 


\section{Введение}

Повышение физико-механических свойств ответственных за безопасность эксплуатации техники литых деталей, работающих при повышенных нагрузках, всегда актуально. Для этого в производстве все чаще требуются отливки из серого чугуна (СЧ) только высоких марок. Улучшение литейно-механических свойств отливок СЧ и сталей невозможно без эффективного легирования и модифицирования чугунов и сталей, позволяющих устранить отбел в чугунных отливках, измельчить зерно, устранить транскристаллизацию, ликвацию, усадку и другие нежелательные явления в сталях [1-6]. Необходимо отметить, что на практике имеется свыше 500 действующих типов различных модификаторов и рафинирующих добавок, содержащих от $2 . . .5$ до 15 компонентов [7]. Из анализа работ по модифицированию [1, 2, 7-18] следует, что кремний выступает наиболее эффективным графитизатором и обязательным компонентом практически всех используемых в промышленности модификаторов. Добавки других элементов, таких как $\mathrm{Ca}, \mathrm{Ba}, \mathrm{Mg}$, $\mathrm{Sr}$ и т.д., используют лишь для усиления эффекта модифицирования и повышения живучести модификаторов [9-11]. Учитывая большое разнообразие способов выплавки чугуна и стали, номенклатуры отливок по массе и их разностенности и для удовлетворения требований современного производства необходимо создание прогрессивных технологий на базе нового поколения комплексных модификаторов, раскислительных смесей, рафинирующих добавок, значительно превышающих эффективность существующих при значительно меньшем расходе. Решению этой задачи и посвящена данная работа.

Цель работы - исследование влияния нанодобавок с повышенной химической активностью углерода и кремния на фазообразование при затвердевании чугуна СЧ с помощью закалки из жидкого состояния.

\section{Проблемные вопросы, теория модифицирования}

В настоящий момент классическая теория зарождения центров кристаллизации $[1,3,5,6]$ не может достаточно полно объяснить формирование структуры отливки чугуна под влиянием модифицирования. Первая сложность заключается в том, что она не учитывает химическое взаимодействие элементов расплава и физическое состояние фаз. Это в свою очередь не позволяет построить теорию модифицирования чугуна, детали которой имеют свои принципиальные особенности. Например, до сих пор не ясно, как с помощью термодинамических и термокинетических факторов можно «управлять» конечной структурой сплава с учетом формирования и развития центров кристаллизации, возникающих в переохлажденном и модифицированном расплаве в результате легирования и модифицирования. Вторая сложность заключается в том, что в настоящее время существует несколько конкурирующих и взаимоисключающих теорий и моделей строения расплава жидкого чугуна. Анализ литературных источников показывает [5-7, 12-16, 19], что создано более 10 конкурирующих теорий модифицирования. К ним следует отнести как традиционные теории - коллоидную, карбидную, полимеризационную, генетическую, так и современные модели - модифицирования III рода, коагуляционную модель, модель динамической микронеоднородности, эмбрионно-кластерную и другие [15]. Для каждой теории и модели характерна своя, особенная «форма» углерода, которая определяет свою, особенную «структуру» расплава чугуна. Очевидно, что в зависимости от постулируемой авторами теорий структуры железоуглеродистого расплава (формы существования углерода)

$$
-673-
$$


разрабатывается и механизм образования центров кристаллизации, и соответствующая этому механизму теория модифицирования. В связи с этим сложилась такая ситуация, что у простой на первый взгляд производственной технологии модифицирования чугуна отсутствует ясная единая теория модифицирования железоуглеродистых расплавов. Причиной разногласий и противоречий в данной теории модифицирования является отсутствие общих принимаемых большинством исследователей представлений в главном вопросе - каков механизм образования центров кристаллизации. Этим можно объяснить и большое количество используемых на практике модификаторов, ибо каждая теория модифицирования требует своего подтверждения через разработку определенного типа модификаторов. Анализируя работы [7, 9, 10, 12, 15, 16] мы провели теоретическое обоснование эффективности использования дисперсных смесевых модификаторов.

\section{Краткое описание наномодификаторов}

Первый состав модификатора (состав 1) состоял из концентрата углеродных нанотрубок и представляет собой чёрный порошок без запаха, химически не токсичен. Исследуемый смесевой модификатор состоит из микрочастиц графита и многостенных углеродных нанотрубок. Наиболее активный компонент - нанотрубки, являются протяжёнными цилиндрическими структурами диаметром от 10 нанометров и длиной до 0,5 мм (рис. 1). Характеристики: химическая формула, состав: $\mathrm{C}-99 \%, \mathrm{SiC}-1 \%$; концентрация нанотрубок: стабильна: $20 \%, 60 \%$, $90 \%$; температура плавления: $3527{ }^{\circ} \mathrm{C}$; температура кипения: $4300{ }^{\circ} \mathrm{C}$; плотность 0,4 г см ${ }^{3}$; теплоёмкость 8,5 Дж/г ${ }^{\circ} \mathrm{C}$; термическое сопротивление: 1,59 Вт/м К.

Второй состав модификатора (состав 2) состоял из наногранул диоксида кремния (8999 \%) и аморфного углерода и представлял собой сыпучий порошок белого цвета. Имеет очень большую удельную поверхность. Материал обладает ненасыщенной структурой алкильного типа с различными типами связей. Нетоксичный, без запаха, не загрязняющий окружающую среду белый порошок со стабильными химическими свойствами. Наногранулы диоксида кремния существенно меняют свойства систем, содержащих обычный микронный оксид кремния (рис. 2). Характеристики: химическая формула, состав: $\mathrm{SiO}_{2} 99$ \%, $\mathrm{SiC} 1$ \%; молекулярный вес: 60,1 г/моль; температура плавления: $1750{ }^{\circ} \mathrm{C}$; температура кипения: $2355{ }^{\circ} \mathrm{C}$; плотность:

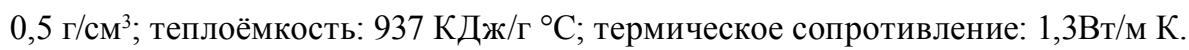

Третий состав (состав 3) состоит из смеси первого и второго составов в пропорции 30 на $70 \%$ (рис. 3).
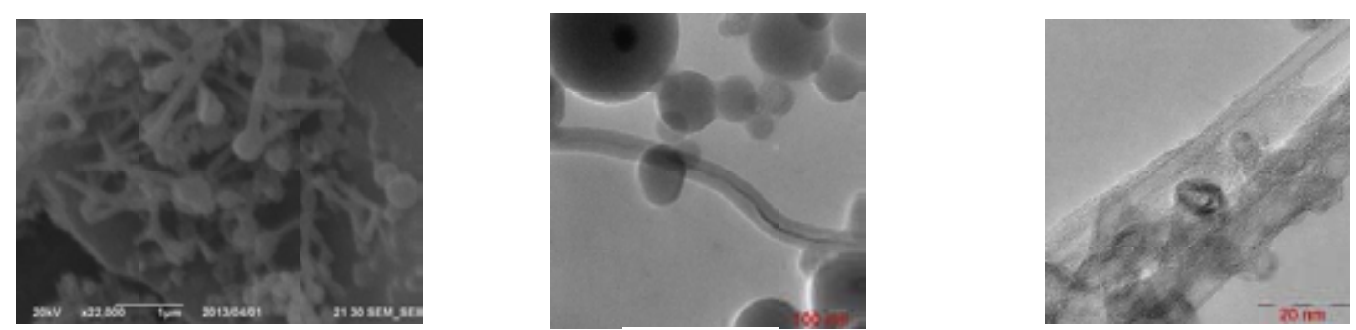

Рис. 1. Электронно-микроскопические фото модификатора из углеродных нанотрубок, полученные при помощи просвечивающей электронной микроскопии 

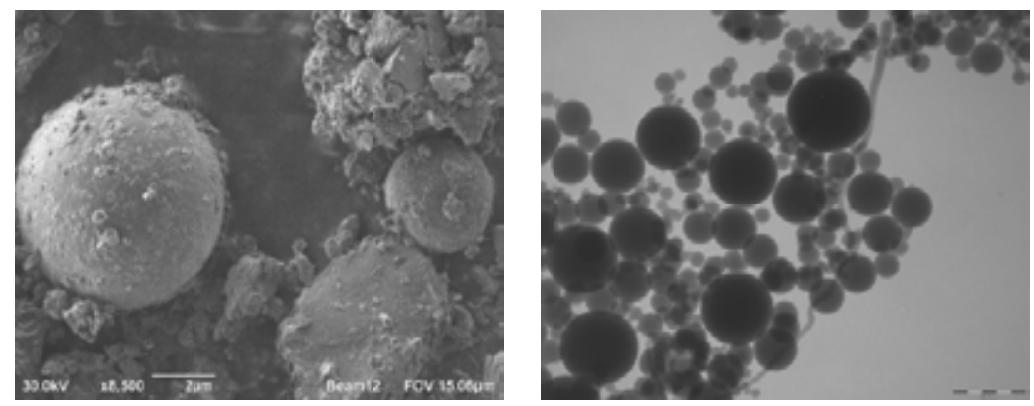

Рис. 2. Электронно-микроскопические фото модификатора, состоящего из наночастиц кремния

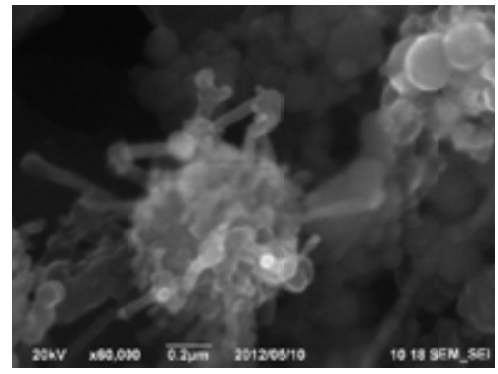

Рис. 3. Электронно-микроскопические фото структур смесевого модификатора - углеродные нанотрубки, сцепленные с шаровидной структурой из кремния

\section{Методика и материалы исследования}

Опыты по определению влияния компонентов смесевого модификатора на процесс модифицирования проводили на сером чугуне марки СЧ10-25 следующего химического состава (табл. 1). Данные марки чугуна выплавляли в индукционной печи марки ИСТ-0,16. Модифицирование чугуна производили при температуре $(1430 \pm 1450){ }^{\circ} \mathrm{C}$, измеряемой термопарой погружения ВР-5/20.

Для модифицирования серого чугуна использовали модификаторы, которые имели химический состав, указанный выше. Брали три типа модификатора: аморфный углерод-нанотрубки (20 \%) (состав 1), наногранулы диоксида кремния (состав 2) и аморфный углерод, нанотрубки (20\%), наногранулы кремния (состав 3). Каждым модификатором обрабатывали по две плавки. Цилиндрические образцы диаметром 16-25 мм отливали в сухие песчаные формы, скорость охлаждения при этом составляла $4,3{ }^{\circ} \mathrm{C} / \mathrm{c}$. Основные характеристики экспериментальной методики приведены в табл. 2. Исследования и опытные выплавки осуществляли на электропечном тигельном агрегате ИСТА-0,4/0,32-И2 (рис. 4) в соответствии с нормативным документом «Технологическая инструкция по выплавке чугуна в печи ИСТА 0,4/0,32». Модифицирование проводили по двум вариантам (рис. 5). Влияние модифицирования оценивали на основании результатов металлографических исследований и анализа механических свойств материалов. Микроструктуру чугунов после механических испытаний исследовали на продольных и поперечных шлифах, в нетравленом и травленом состояниях. Исходную микроструктуру чугуна оченивали по ГОСТ 3443-87.

$$
-675-
$$


Таблица 1. Характеристики серых чугунов

\begin{tabular}{|c|c|c|c|c|c|}
\hline \multirow{2}{*}{ Марка чугуна } & \multicolumn{5}{|c|}{ Массовая доля элементов, \% } \\
\cline { 2 - 6 } & Углерод & Кремний & \multirow{2}{*}{ Марганец } & Фосфор & Сера \\
\cline { 2 - 6 } & & & $0,5-0,8$ & 0,3 & 0,15 \\
\hline СЧ10 & $3,5-3,7$ & $2,2-2,6$ & $0,5-0,8$ & 0,2 & 0,15 \\
\hline СЧ15 & $3,5-3,7$ & $2,0-2,4$ & $0,7-1,0$ & 0,2 & 0,15 \\
\hline СЧ20 & $3,3-3,5$ & $1,4-2,4$ & $0,7-1,0$ & 0,2 & 0,15 \\
\hline СЧ25 & $3,2-3,4$ & $1,4-2,2$ & & & \multicolumn{2}{|c|}{ не более } \\
\hline
\end{tabular}

Таблица 2. Основные характеристики процесса подготовки образцов серого чугуна

\begin{tabular}{|c|c|}
\hline Параметр & Значение \\
\hline Плавильная печь марки ИСТ-0,16 & Объем печи 250 кг, ковш 120 кг \\
\hline Шихтовые материалы & $\begin{array}{l}\text { Передельный чугун (25 \%), стальной лом (50 \%), } \\
\text { лома серого чугуна }(10 \text { \%), бой графитовых } \\
\text { электродов, ферромарганец (80 \% Mn), } \\
\text { феррофосфор (26 \% Р) и сульфид железа } \mathrm{FeS}_{2}\end{array}$ \\
\hline Состав чугуна (перед модифицированием) & Таблица 1 \\
\hline Способ модифицирования & В ковше \\
\hline Расход модификатора & 0,01-1 \% масс. \\
\hline $\begin{array}{l}\text { Модификаторы на основе C-Si : } \\
\text { - состав } 1-92 \% \mathrm{C} \% \\
\text { - состав } 2 \mathrm{C}-\mathrm{Si}(78-80 \% \mathrm{Si}) \\
\text { - состав } 3-\mathrm{C}(40 \%-\mathrm{Si} 60 \%)\end{array}$ & \\
\hline Температура перегрева & $\mathrm{T}_{\mathrm{s}}=1460-1480{ }^{\circ} \mathrm{C}$ \\
\hline Температура модифицирования & $\mathrm{T}_{\mathrm{in}}=1430-1450{ }^{\circ} \mathrm{C}$ \\
\hline Температура разливки & $\mathrm{Tp}=1400-1420^{\circ} \mathrm{C}$ \\
\hline Цилиндрические образцы & Диаметром 25-35 мм, песчаная форма \\
\hline
\end{tabular}

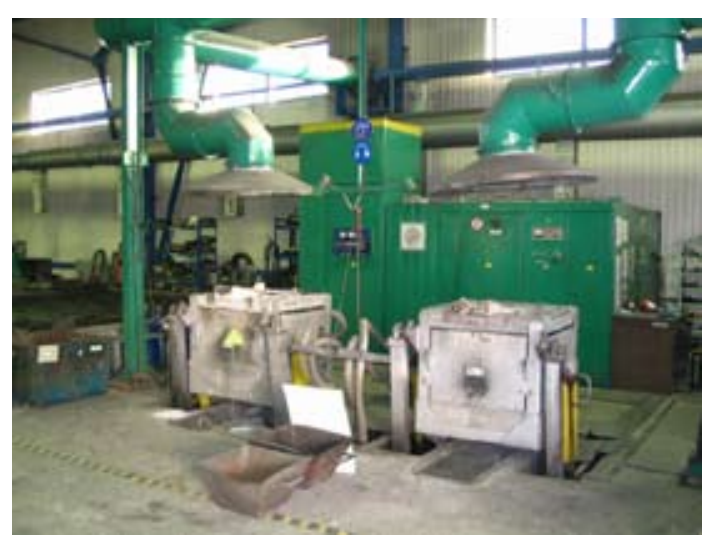

Рис. 4. Участок проведения опытно-промышленных испытаний 


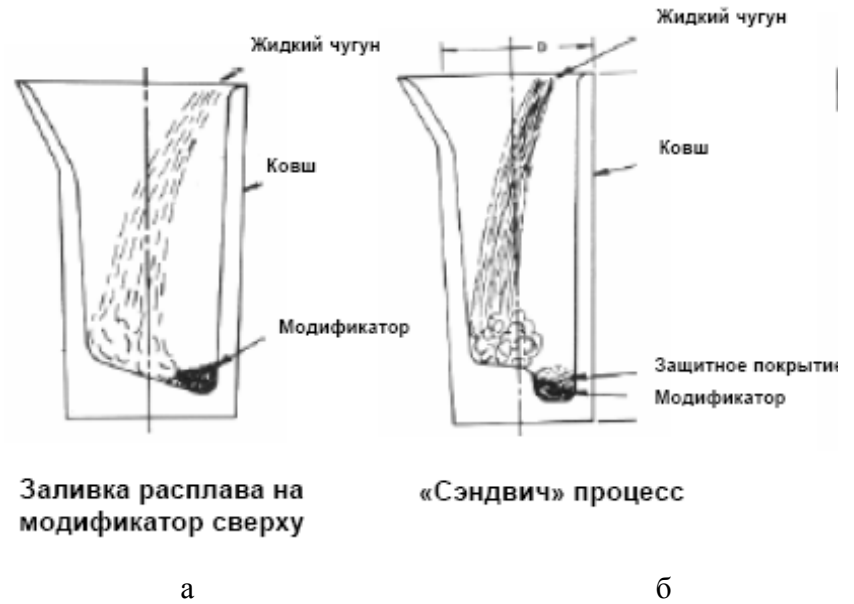

Рис. 5. Примеры ковшей для модифицирования методами а - заливки расплава на модификатор; б «сандвич»-процесса

\section{Результаты экспериментов и обсуждение}

Выплавка серого чугуна происходила в стандартном режиме плавки согласно действующей технологической инструкции. На первом этапе оценивали графитизирующие свойства состава 1. В операции выплавки модифицированного чугуна был изменен единственный параметр плавки - произведена замена 50 \% стандартного металлургического графита на состав 1 , состоящий из дисперсного графитизированного углерода с содержанием $0,20 \%$ масс. углеродных многослойных нанотрубок (табл. 3). Выплавка проводилась при открытом тигле, рабочей температуре процесса $1500^{\circ} \mathrm{C}$, время выплавки от начала процесса 2,5 ч, введение графитизированного углерода с нанотрубками осуществлялось в середине процесса.

Анализ прочностных характеристик показал, что временное сопротивление на разрыв опытного модифицированного образца чугуна составило $270 \mathrm{MПа,} \mathrm{что} \mathrm{значительно} \mathrm{выше}$ по сравнению с образцом свидетелем, который имеет временное сопротивление 210 МПа. На следующем этапе испытания оценили влияние состава модификатора на механические свойства серого чугуна СЧ15. Для этого провели несколько плавок с разной навеской модификатора (состава 1). Модифицирование проводили по схеме рис. 5, заливка расплава на модификатор в ковше. Результаты представлены в табл. 4. Сравнивая три серии экспериментов образца серого чугуна СЧ15 с разной степенью модифицирования, видим, что механические свойства повышаются и соответствуют по ГОСТ 1412-85 марке СЧ20 и СЧ25. Можно констатировать, что использование модификатора под маркой состава 1 , имеющего в своем составе 20 \% нанотрубок, существенно повышает механические свойства серого чугуна типа СЧ10,15.

Была проведена серия экспериментов при выплавке чугуна СЧ15 по схеме «сэндвич»процесса (рис. 5) с модификатором (состав 1), которая не выявила существенных различий в механических свойствах модифицированных образцах в зависимости от способа введения. Этот факт противоречит устойчивому мнению преимущества «сэндвич»-процесса модифицирования $[4,10,18]$.

$$
-677-
$$


Таблица 3. Сравнительный анализ опытного чугуна и чугуна-свидетеля

\begin{tabular}{|l|c|c|c|c|c|c|c|c|c|c|c|}
\hline \multirow{2}{*}{ Образец } & \multicolumn{10}{|c|}{ Содержание, \% } \\
\cline { 2 - 13 } & $\mathrm{C}$ & $\mathrm{Si}$ & $\mathrm{Mn}$ & $\mathrm{P}$ & $\mathrm{S}$ & $\mathrm{Ni}$ & $\mathrm{Al}$ & $\mathrm{Cu}$ & $\mathrm{Ti}$ & $\mathrm{V}$ & $\mathrm{Fe}$ \\
\hline Опыт & 3,62 & 2,834 & 0,695 & 0,4722 & 0,045 & 0,126 & 0,0012 & 0,157 & 0,011 & 0,0095 & 93,2 \\
\hline Свид & 3,59 & 2,685 & 0,733 & 0,4343 & 0,0475 & 0,249 & 0,0023 & 0,1663 & 0,0121 & 0,0076 & 93,5 \\
\hline
\end{tabular}

Таблица 4. Результаты испытаний модификатора состава 1

\begin{tabular}{|c|c|c|c|c|c|}
\hline \multirow{2}{*}{ Образец } & \multicolumn{2}{|c|}{ Масса в ковше, } & \multirow{2}{*}{$\begin{array}{l}\text { Твердость, } \\
\text { МПа }\end{array}$} & \multirow{2}{*}{$\begin{array}{c}\text { Временное } \\
\text { сопротивление, } \\
\text { НВ }\end{array}$} & \multirow{2}{*}{$\begin{array}{c}\text { Марка } \\
\text { (ГОСТ 1412-85) }\end{array}$} \\
\hline & 120 кг & модификатор & & & \\
\hline Исходный & - & - & $185-210$ & 168-178 & СЧ10, СЧ15 \\
\hline №1 & & $120 \Gamma$ & 263 & 240 & СЧ 25 \\
\hline №2 & & 77 г & 260 & 270 & СЧ 25 \\
\hline №3 & & 46 г & 233 & 200 & СЧ 20 \\
\hline
\end{tabular}

Следующим этапом исследования была оценка модификатора состава 2. Для этого провели несколько плавок с разной концентрацией модификатора (состава 2). Модифицирование проводили по схеме (рис. 5), заливка расплава на модификатор в ковше и «сэндвич»-процесс. Результаты представлены в табл. 5. Проведенная оценка модификатора (состава 2) показала существенное повышение механических свойств серых чугунов марки СЧ10, 15, 25. Вместе с тем необходимо отметить изменения в химическом составе модифицированных образцов: во всех образцах, модифицированных составом 2, наблюдалось повышение содержания кремния, фосфора и серы. По всей видимости, это связано с тем, что сера и фосфор в качестве неудаленных солей присутствуют в модификаторе (состав 2). Для уточнения этого предположения необходимо провести дополнительные исследования модификатора состава 2 с разной степенью очистки от загрязнений.

Полученные результаты с использованием модификатора состава 2 можно в первом приближении объяснить следующим образом. Известно, что серый чугун обладает рядом принципиальных особенностей. Одной из особенностей является факт [3, 6], что частицы (атомы) жидкого затвердевающего чугуна сегрегационно разделяются, что говорит об изменении энергии связи между атомами железа и углерода в момент затвердевания. У атомов углерода возрастает доля ковалентных связей в ковалентно-металлической связи с атомами железа. Ковалентные связи более сильные и способны прочно удерживать атомы. Это обстоятельство, возможно, становится определяющим и приводит к тому, что наибольшую устойчивость атомы углерода получают в случае, когда они объединяются и образуют агрегатные комплексы, кластеры [1315]. В обычных же условиях кристаллизации графитные комплексы располагаются между ветвями аустенитного дендрита [15]. Таким образом, на практике для состава модификатора из наногранул диоксида кремния (89-99 \%) и аморфного углерода важную роль играет возможность кластерного зародышеобразования графитных включений в чугуне за счет большого содержания кремния, усиливающего образование и рост включений первых зародышей графита.

$$
-678-
$$


Таблица 5. Результаты испытаний модификатора состава 2

\begin{tabular}{|c|c|c|c|c|c|}
\hline \multirow{2}{*}{ Образец } & \multicolumn{2}{|c|}{ Масса в ковше } & \multirow{2}{*}{$\begin{array}{c}\text { Твердость, } \\
\text { МПа }\end{array}$} & \multirow{2}{*}{$\begin{array}{c}\text { Временное } \\
\text { сопротивление, } \\
\text { НВ }\end{array}$} & \multirow{2}{*}{$\begin{array}{c}\text { Марка } \\
\text { (ГОСТ 1412-85) }\end{array}$} \\
\hline & 120 кг & модификатор, г & & & \\
\hline $\begin{array}{l}\text { Исходный, заливка } \\
\text { модификатора }\end{array}$ & - & - & $185-210$ & $168-180$ & СЧ10, СЧ15 \\
\hline № 1 & & 120 & 220 & 240 & СЧ25 \\
\hline № 2 & & 77 & 210 & 270 & СЧ25 \\
\hline № 3 & & $46 \Gamma$ & 190 & 200 & СЧ20 \\
\hline \multicolumn{6}{|l|}{ «Сандвич»-процесс } \\
\hline исходный & - & - & $185-210$ & $168-180$ & СЧ10,СЧ15 \\
\hline № 1 & & 120 & 363 & 240 & СЧ25 \\
\hline № 2 & & 77 & 360 & 270 & СЧ 25 \\
\hline № 3 & & 46 & 190 & 200 & СЧ20 \\
\hline $\begin{array}{l}\text { Исходный, заливка } \\
\text { модификатора }\end{array}$ & - & - & $210-230$ & 240 & СЧ 25 \\
\hline № 1 & & 120 & 363 & 310 & СЧЗ30 \\
\hline № 2 & & 77 & 260 & 290 & СЧЗ \\
\hline № 3 & & 46 & 210 & 250 & СЧ 25 \\
\hline
\end{tabular}

Таблица 6. Результаты испытания модификатора состава 3

\begin{tabular}{|c|c|c|c|c|c|}
\hline \multirow{2}{*}{ Образец } & \multicolumn{2}{|c|}{ Масса в ковше, } & \multirow{2}{*}{$\begin{array}{c}\text { Твердость, } \\
\text { МПа }\end{array}$} & \multirow{2}{*}{$\begin{array}{c}\text { Временное } \\
\text { сопротивление, } \\
\text { НВ }\end{array}$} & \multirow{2}{*}{$\begin{array}{c}\text { Марка } \\
\text { (ГОСТ 1412-85) }\end{array}$} \\
\hline & 120 кг & модификатор, г & & & \\
\hline Исходный & - & - & $185-210$ & $168-178$ & СЧ10, СЧ15 \\
\hline № 1 & & 120 & 263 & 310 & СЧЗ \\
\hline № 2 & & 77 & 260 & 270 & СЧЗЗ \\
\hline № 3 & & 46 & 233 & 240 & СЧ 25 \\
\hline
\end{tabular}

Далее оценивали модификатор смесевого модификатора состава 3. Для этого, как и в экспериментах, описанных выше, провели несколько плавок с разной концентрацией модификатора состава 3. Модифицирование шло по схеме рис. 5, т.е. заливка расплава на модификатор в ковше. Результаты представлены в табл. 6. Смесевой модификатор состава 3 в сравнении с результатами других составов дал наилучшие показатели механических свойств серых чугунов.

Результаты исследований модификатора состава 3 можно интерпретировать следующим образом (это подтверждается результатами работ других авторов [16-18]). Известно, что технология модифицирования предусматривает разливку жидкого раствора серого чугуна в ковше на добавку модификатора. Тогда, согласно нашей гипотезе, описанной выше, модифицированный расплав можно рассматривать как разбавленную суспензию, в которой дисперсной фазой являются частицы модификатора, а дисперсионной средой - расплав, находящийся по объему на этом этапе в неравновесных термодинамических условиях. Частицы дисперсного смесевого модификатора кремния хорошо, а углерода удовлетворительно смачиваются жид-

$$
-679-
$$


ким чугуном. Технология заливки в ковш подразумевает существование гидродинамического перемешивания модификатора по всему объему ковша и способна обеспечить относительно равномерное распределение наномодификатора по всему объему. Одновременно с этим дисперсные частицы модификатора начинают растворяться и создают локальные неравновесия по всему объему ковша. Поскольку за этапом модифицирования следует этап заливки литейных форм, то на локальные концентрационные неравновесия в объеме ковша накладываются дополнительно термодинамические неравновесия, вызванные снижением температуры на поверхности расплава и в объеме. Из работ $[3,6,8,11]$ известно, что с понижением температуры происходят смещения границ двухфазных областей $\alpha+Ж$ и $\gamma+Ж$, а также трехфазной области перитектического равновесия $\alpha+\gamma+Ж$. Жидкий раствор (Ж) серого чугуна становится по всему затвердевающему объему двухфазной областью $\gamma+Ж$. Состояние этой области будет претерпевать дополнительные изменения под влиянием растворяющихся частиц $\mathrm{Si}$ и C модификатора. В области каждой частицы кремния возникает избыток атомов кремния, переходящих в жидкость (Ж), и происходит, соответственно, рост плотности валентных электронов, которые стремятся стать коллективизированными. Эти два фактора способны изменить гранецентрированную упаковку атомов железа на менее плотную объемно-центрированную, которая слабо растворяет и поддерживает диффузию атомов углерода. Кратковременный избыток валентных электронов, созданный частицами кремния, помогает атомам углерода перейти в свободное невозмущенное состояние, погасить дефицит парциальной энергии и восстановить свою активность. В невозмущенном состоянии атомам углерода легче усиливать ковалентные связи. Отсюда непосредственно следует, что частицы кремния создают вокруг себя перитектическую трехфазную область $[6,11,23]$, а углерод, став избыточным компонентом, получает возможность покинуть те, ставшие неустойчивыми, места в решетке $\gamma$-Fe, которые он занимал ранее при устойчивом состоянии металлического раствора. Растворение модификатора состава 3 происходит по вышеописанному механизму и создает в нем структурные элементы (кластеры), обогащенные Si. Они равномерно распределяются в расплаве и контактируют со структурными элементами $C$. Благодаря высокому содержанию $S i$ свободные частицы $C$ дисперсных слоистых $F e-C$-структур располагаются и графитизируются вдоль кластеров $S i$. Это приводит к расщеплению пластин графита. Тем самым создаются кинетические условия для формирования тонко разветвленного графита. Кроме того, $S i$ в чугуне при повышенном его содержании начинает вступать в расплаве во взаимодействие с $C$ и образовывать соединения $\mathrm{SiC}$. Данная гипотеза требует дополнительной экспериментальной проверки.

Для исследования на оптической и СЭМ модели JIB-Z4500 были взяты образцы чугуна СЧ15, 25 для исследования структур и фактографии изломов после испытаний прочности на разрыв. Исследование поверхности образцов с помощью сканирующей электронной микроскопии показало существенные различия в структуре поверхности металлов, что можно увидеть на рис. 6 и 7. Все исследуемые материалы имеют структуру серого чугуна на феррите - перлитной основе с графитом пластинчатой прямолинейной формы типа ПГф1 у немодифицированных образцов (рис. $6 a, \sigma)$. Модифицированные образцы имею форму включений графита типа ПГф4 гнездообразной завихренной формы (рис. $7 a, 6$ ). Содержание феррита составляет $~ 8 \%$ по ГОСТ Ф8. В контрольном сплаве графит ПГр1 равномерно распределен по объему материала, содержание феррита больше и составляет 45 \% по ГОСТ-Ф55. Средняя длина включений со- 


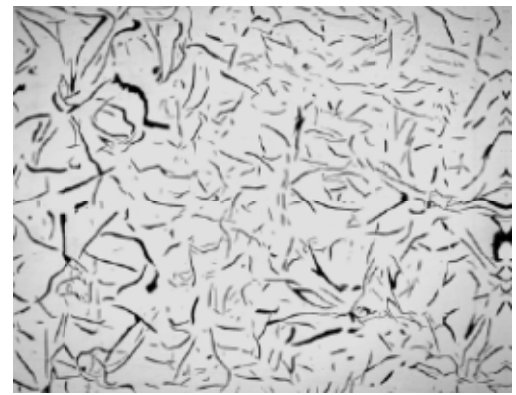

a

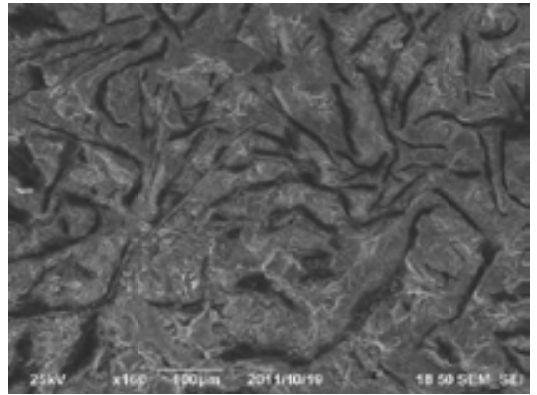

6

Рис. 6. Исходная структура серого чугуна марки СЧ15 с графитом пластинчатый прямолинейным ПГф1: $\mathrm{a}$ - оптический микроскоп; б - сканирующий электронный

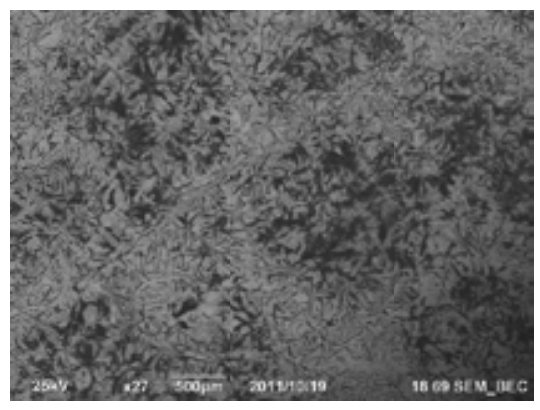

a

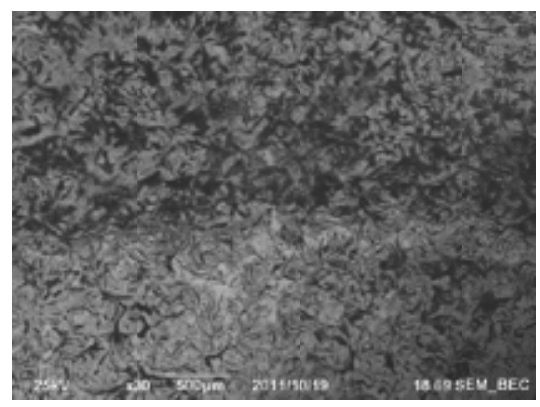

6

Рис. 7. Структура чугуна СЧ 15 после модифицирования: а - составом 2 и составом 3; б - форма графита изменилась на гнездообразную ПГф4

ставляет $\sim 500$ мкм, по ГОСТ-ПГд750 (рис. $6 a$ ). Расстояние между цементитными пластинами равно 1-5 мкм. В модифицированном образце распределение графита обладает менее однородной структурой. Средняя длина пластин графита 100 мкм. Однако встречаются области, в которых графитные включения имеют розеточное распределение и составляют в длину $30-50$ мкм (рис. 7б). Дисперсность пластин феррита - цементитной смеси - в модифицированных образцах примерно одинакова. Практически во всех рассматриваемых сплавах присутствует фосфидная эвтектика. Включения эвтектики распределены равномерно при модифицировании составом 1, средняя площадь включений равняется 500 мкм² ФЭд400 (рис. 6).

При модифицировании составом 2 включения эвтектики распределены неравномерно, средняя площадь включений не превышает 200 мм²$^{2}$ ФЭд250. В образцах модифицирования составом 3 не выявлено значительных изменений в форме и распределении фосфидной эвтектики. В исследуемых модифицируемых образцах наблюдаются графитные включения двух типов. В большей части объема присутствуют равномерно распределенные включения завихренной формы (розеточной) ПГр7, длина которых составляет 100-150 мкм. В то время как у немодифицированных образцов наблюдаются колонии пластинчатого графита типа ПГр3. Второй тип графита представляет собой мелкие пластины длиной до 10-30 мкм, расположен-

$$
-681-
$$


ные в междендроидном пространстве. В результате модифицирования чугуна СЧ15 составом 3 увеличивается дисперсность структурных составляющих пластинчатого перлита. Анализ результатов исследований графитизирующей способности модификатора с наноструктурами показал, что его введение в расплав серого чугуна позволяет снизить выделение свободного феррита в микроструктуре чугуна до 5-8 \% при неизменной твёрдости НВ 207-217, а также способствует получению наиболее благоприятной морфологии графита - ПГр1 (росту более крупных пластинок графита одинакового размера) - и более равномерному его распределению по объёму металлической матрицы. Проведенные исследования микроструктур после механических испытаний образцов чугуна СЧ30, модифицированного составом 3 , установили наличие включений шаровидного графита.

Известно, что включения графита, особенно пластинчатой формы, действуют на металлическую основу чугуна как надрезы, снижающие ее механическую прочность и пластичность. Наиболее высокими механическими свойствами обладают высокопрочные чугуны с шаровидной формой графита и ковкие чугуны, в которых благодаря специальной термической обработке обеспечивается выделение углерода отжига в виде хлопьевидных частиц [1-3, 24]. В практике производства отливок из модифицированного чугуна в структуре последнего графит имеет зачастую не только шаровидную (или компактную вермикулярную) форму, а и смешанную с различной долей пластинчатого, шаровидного или компактного графита. Для количественной оценки усредненной степени сфероидизации графита (ССГ) стандарт (ГОСТ 3443-85) таких шкал не содержит.
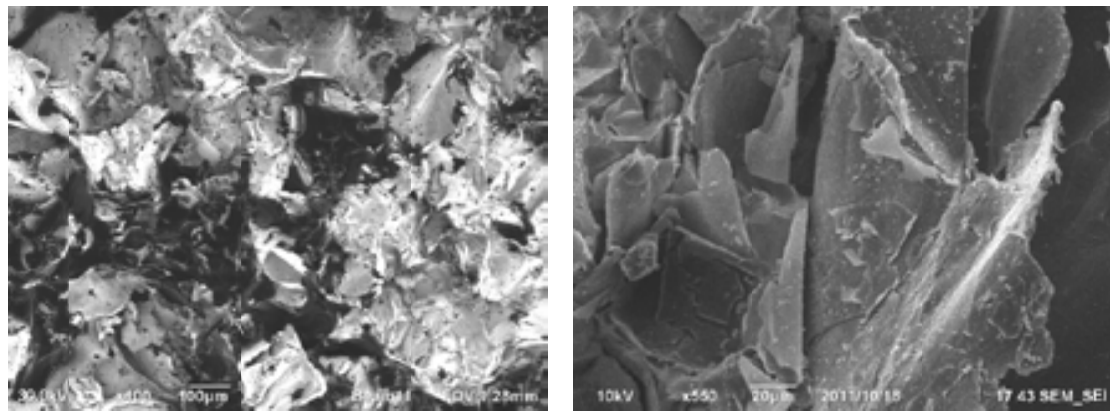

Рис. 8. Фактография излома немодифицированного образца серого чугуна марки СЧз0
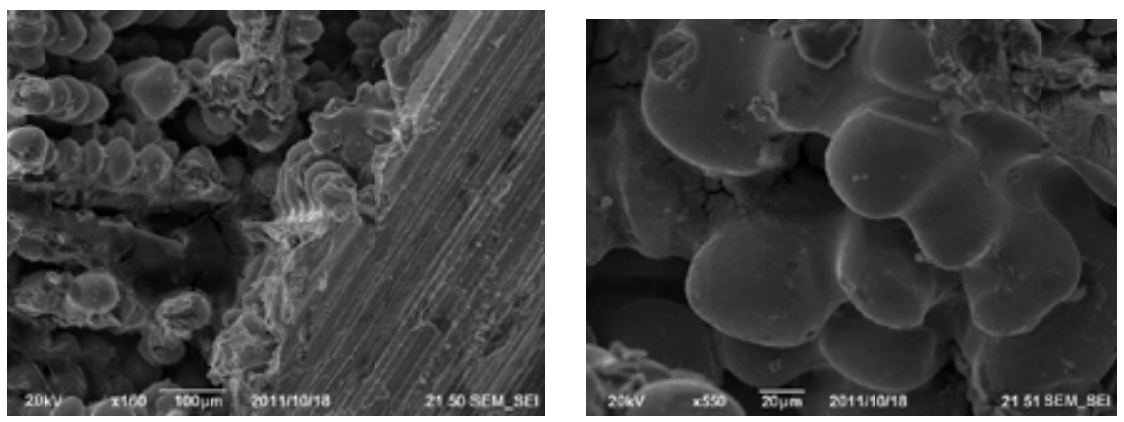

Рис. 9. Фрактография модифицированного составом 3 образца серого чугуна марки СЧ30 
В нашем случае модифицирование дает смешанную структуру формы графита, что затрудняет ее классификацию, но позволяет объяснить высокий комплекс механических свойств после модифицирования нанодобавками за счет формирования глобулярной формы графита в объеме слитка.

\section{Выводы}

1. Введение в небольших количеств модификатора с наноразмерными структурами при разливке металла приводит:

- к увеличению содержания перлита в металлической основе;

- к изменению формы графитовых включений чугуна с пластинчатой на гнездообразную (розеточную), шарообразную (глобулы);

- к увеличению прочности до 35-50 \%.

2. Выбранные для модифицирования область размеров и массовая доля ультрадисперсных частиц соответствуют механизму дисперсионно упрочненного сплава.

3. На примере модифицирования серого чугуна показано, что дисперсный состав существенно влияет на степень изменения морфологии графитовых включений.

\section{Список литературы}

[1] Бунин К.П., Таран Ю.Н. Строение чугуна. М.: Металлургия, 1972. 160 с. [Bunin К.P., Taran Yu.N. The structure of cast iron. Moscow, Metallurgiya, 1972, 160 p. (in Russian) ]

[2] Горшков А.А. О механизме образования шаровидного графита. Литейное производство, 1955, 3, 17 - 21 [Gorshkov A.A. On the mechanism of formation of spherical graphite, Liteinoe proizvodstvo, 1955, 3, 17-21 (in Russian)]

[3] Лахтин Ю. М., Леонтьева В. П. Материаловедение. М.: Машиностроение, 1990. 525 с. [Lakhtin Yu.M. Leontieva V.P. Material science. Moscow, Mashinostroenie, 1990, 525 p. (in Russian)]

[4] Чуркин Б.С. [и др.]. Технология литейного производства. Екатеринбург: УГППУ, 2000. 396 c. [Churkin B.S. et al. Technology of foundry production. Yekaterinburg, UGPPU, 2000, 396 p. (in Russian)]

[5] Леви Л.И., Мариенбах А.М.. Основы теории металлургических процессов и технология плавки литейных сплавов. М.: Машиностроение, 1970. 496 с. [Levi L.I., Marienbah A.M. Basic theory of metallurgical processes and smelting technology of casting alloys, Moscow, Mashinostrioenie, 1970, 496 p. (in Russian)]

[6] Гиршович Н. Г. Справочник по чугунному литью. М.-Л.: Машиностроение, 1978. 758 с. [Girshovich N.G. Handbook of cast iron casting, Moscow - Leningrad, Mashinostroenie, 1978, 758 p. (in Russian)]

[7] Давыдов С.В., Панов А.Г. Тенденции развития модификаторов для чугуна и стали. Заготовительное производство в махиностроении, 2007, 1, 3-12 [Davydov S.V., Panov A.G. Tendencies of development of modifiers for the iron and steel, 2007, 1, 3-12 (in Russian)]

[8] Витусевич В.Т., Билецкий А.К., Шумихин В.С. Расплавы, 1989, 3, 5-8 [Vitusevich V.T., Biletskiy A.K., Shumikhin V.S. Rasplavy, 1989, 3 5-8 (in Russian)]

[9] Бубликов В.Б. Повышение модифицирующего воздействия на структурообразование в высокопрочном чугуне. Литейное производство, 2003, 8, 20-22 [Bublikov B.V. Increasing of

$$
-683-
$$


modifying influence on structure formation in ductile iron. Liteinoe proizvodstvo, 2003, 8, 20-22 (in Russian)]

[10] Леках С. Н., Шейнерт В. А. Методы повышения эффективности графитизирующего модифицирования чугунов. Литейное производство, 1994, 9, 4-6 [Lekakh S.N., Sheinert V.A. Methods to improve the efficiency of graphitizing inoculation of cast irons. Liteinoe proizvodstvo, 1994, 9, 4-6 (in Russian)]

[11] Гаврилин И. В. Строение жидкой и твердой фаз в литейных сплавах в твердожидкм состоянии. Металлургия машиностроения, 2003, 6, 9-11 [Gavrilin I.V. The structure of the liquid and solid phases in cast alloys in solid-liquid state. Metallurgiya mashinostroeniya, 2003, 6, 9-11 (in Russian) ]

[12] Давыдов С. В. Новый подход к классификации методов модифицирования. Металлургия машиностроения. 2006, 5, 5-9 [Davydov S.V. A new approach to the classification of the modification methods, Metallurgiya mashinostroeniya, 2006, 5, 5-9 (in Russian)]

[13] Закирничная M. М. Образование фуллеренов в углеродистых сталях и чугунах при кристаллизации и термических воздействиях. Дис. на соиск. уч. ст. д-ра техн. наук. Уфа, 2001, 211c. [Zakirichnaya M.M. Fullerene formation in carbon steels and cast irons during the crystallization and thermal influences, Dis. na soisk. uch. st. d-ra tehn. nauk, Ufa, 2001, 211 p. (in Russian)]

[14] Гаврилин И. В. Кластеры - фуллерены - фракталы в жидких литейных сплава. Металлургия машиностроения, 2004, 5, 30-33 [Gavrilin I.V. Clusters - fullerenes - fractals in liquid casting alloys, Metallurgiya mashinostroeniya, 2004, 5, 30-33 (in Russian)]

[15] Кураков Ю.Г., Чайкин В.А., Чайкин А.В. Повышение механических свойств серых чугунов. Литейное производство. 2002, 7, 9-11 [Kurakov Yu.G., Chaikin V.A.,Chaikin A.V. Improving the mechanical properties of gray cast iron, Liteinoe proizvodstvo, 2002, 7, 9-11 (in Russian)]

[16] Семенов В.И., Чайкин А.В., Малихин В.М., Уханов Ю.А., Малов И.А., Петров Н.Р. Фазовые и структурные изменения в чугуне после модифицирования, Литейное производство, 2006, 10, 7-9 [Semenov V.I., Chaikin A.V., Malikhin V.M., Ukhanov Yu. A., Malov I.A., Petrov N.R. Phase and structural changes in the iron after inoculation, Liteinoe proizvodstvo, 2006, 10, 7-9 (in Russian)]

[17] Болдырев Д.А., Чайкин А.В. Новые смесевые модификаторы для инокулирующей обработки чугунов, Литейщик России, 2007, 3, 32-36 [Boldyrev D.A., Chaikin A.V. New mixed modifiers for inoculating of cast iron, Liteistchik Rossii, 2007, 3, 32-36 (in Russian)]

[18] Афанасьев А.Д., Иванов Н.А., Ржечицкий А.Э., Кондратьев В.В. Наночастицы углерода в отходах производства алюминия и их модифицирующие свойства. Вестник Иркутского государственного технического университета, 2009, 4, 39-44 [Afanasiev A.D., Ivanov N.A., Rzhechitskiy A.E. Kondratiev V.V. Carbon nanoparticles in waste production of aluminum and their modifying properties, Vestnik Irkutskogo gosudarstvennogo tekhnicheskogo universiteta, 2009, 4, 39-44 (in Russian)]

[19] Кондратьев В.В., Иванов Н.А., Ржечицкий Э.П., Сысоев И.А. Перспективы применения нанотехнологий и наноматериалов в горно-металлургической промышленности, Вестник Иркутского государственного технического университета, 2010, 1, 168-174 [Kondratiev V.V., Ivanov N.A., Rzhechitskiy E.P., Sysoev I.A. Prospects for the use of nanotechnology and nanomateri- 
als in the mining industry, Vestnik Irkutskogo gosudarstvennogo tekhnicheskogo universiteta, 2010, 1, 168-174 (in Russian)]

[20] Кондратьев В.В., Мехнин А.О., Иванов Н.А., Богданов Ю.В., Ершов В.А. Исследования и разработка рецептуры наномодифицированного чугуна для ниппелей анодов алюминиевых электролизеров, Металлург, 2012, 1, 69-71 [Kondrat'ev V.V., Mekhnin A.O., Ivanov N.A., Bogdanov Yu.V., Ershov V.A. Research and development of composition of nanoinoculated cast iron for anodes stubs of aluminium pots, Metallurg, 2012, 69-71 (in Russian)]

[21] Кондратьев В.В., Немчинова Н.В., Иванов Н.А., Ершов В.А., Сысоев И.А. Новые технологические решения по переработке отходов кремниевого и алюминиевого производств, Металлург, 2013, 5, 92-95. [Kondratyev V.V., Nemchinova N.V., Ivanov N.A., Ershov V.A., Sysoev I.A. New technological solutions for wastes processing of silicon and aluminum production, Metallurg, 2013, 5, 92-95 (in Russian)]

[22] Ершов В.А., Кондратьев В.В., Сысоев И.А., Мехнин А.О. Извлечение наночастиц углерода из фторированного глинозема при производстве алюминия, Металлург, 2012, 12, 74 78 [Ershov V.A., Kondrat'ev V.V., Sysoev I.A., Mekhnin A.O. Extraction of carbon nanoparticles from fluorinated alumina in aluminum production, Metallurg, 2012, 12, 74-78 (in Russian)]

[23] Кондратьев В.В., Балановский А.Е., Иванов Н.А., Ершов В.А., Корняков М.В. Оценка влияния состава модификатора с наноструктурными добавками на свойства серого чугуна, Металлург, 2014, 5, 48-56 [Kondratiev V.V., Balanovskiy A.E., Ivanov N.A., Ershov V.A., Kornyakov M.V. Impact assessment of modifier composition with nanostructured additives on properties of grey cast iron, Metallurg, 2014, 5, 48-56 (in Russian)]

[24] Кондратьев В.В., Ершов В.А., Балановский А.Е., Иванчик Н.Н., Карлина А.И. Наноструктуры и алюминиевая промышленность, Вестник Иркутского государственного технического университета, 2015, 8(103), 77-86 [Kondrat'ev V.V., Ershov V.A., Balanovskiy A.E., Ivanchik N.N., Karlina A.I. Nanostructures and aluminum industry, Vestnik Irkutskogo gosudarstvennogo tekhnicheskogo universiteta, 2015, 8(103), 77-86 (in Russian)] 